\title{
The Stature of Human Thyroid Cancer Related to Over Expressed mir-221 and mir-146b
}

Jamshid Molaei, Melika Meidanchi and Sina Mirzaahmadi*

Department of the Genetics, Zanjan branch, Islamic Azad University, Zanjan, Iran

\begin{abstract}
Purpose: The ability of miRNAs for biomarker tools was further built by recent research showing that cancerspecific miRNAs are traceable in cell-free blood fluids such as plasma and serum. In this study, the levels of miR-221 and miR146b in human's peripheral blood as tumor markers for early detection of Papillary Thyroid Carcinoma [PTC] were investigated.
\end{abstract}

Methods: A stem-loop quantitative reverse transcription-polymerase chain reaction [qRT-PCR] method was performed to determine the serum levels of miR-221 and miR-146b from 25 healthy controls, 25 PTC patients the day before thyroidectomy, 25 patients with benign nodules and 25 patients after thyroidectomy during the scheduled medical examinations.

Results: There was statistical difference in the serum levels for miR-221 and miR-146b between the controls and the PTC patients. It also showed no statistical difference for miR-221 and miR-146b between controls and thyroidectomy patients.

Conclusion: The overexpression of miR-221 and miR-146b could be potentially served as serum indicator biomarkers in the approach for Thyroid Papillary Carcinoma detection from benign nodules.

Keywords: microRNAs; Papillary Thyroid Carcinoma [PTC]; qRT-PCR; Biomarkers

\section{Introduction}

Thyroid nodules are a very frequent pathology among common population. Despite the vast majority of them are of benign origin, the incidence of thyroid cancer is currently rather rising [1]. Papillary thyroid carcinoma (PTC) is the most common form of thyroid cancer, comprising about $85 \%$ of all thyroid cancer [2]. Fine needle aspiration (FNA) biopsy is the gold standard for diagnosing thyroid nodules. However, $10 \%$ to $15 \%$ of these biopsies are inconclusive, ultimately requiring a diagnostic thyroid lobectomy [3]. FNA is an invasive diagnostic method and heavily dependent on the technical performance and experience of the operators. Thus, considerable effort has been made to identify other reliable markers for primary PTC [4]. Several types of ancillary approaches have been used to improve the diagnostic yield of FNA biopsies in determinate thyroid nodules. These include immuno-histochemical stains, microRNAs, gene mutations/ rearrangements, and gene expression panels [5]. MicroRNAs (miRNAs) are 22- to 25-nucleotide non-coding RNA molecules that typically prohibit protein production by binding to the 3 ' untranslated region [UTR] of specific target mRNAs [6]. Each microRNA has the distinct capability to potentially regulate the expression of hundreds of coding genes and thereby modulate several cellular pathways including proliferation, apoptosis and stress response [7]. In addition to their roles in normal physiology, miRNAs are frequently dysregulated in cancer. This paradigm suggests that miRNAs could be clinically useful cancer biomarkers. The potential of miRNAs for biomarker applications was further reinforced by recent research showing that cancer-specific miRNAs are detectable in cell-free blood fluids such as serum and plasma [8]. Searching literature for published studies to identify which miRNAs altered expression has related to PTC, revealed that PTC has associated with MiR-221 and MiR-146b over expression [9]. MiR-221 is among the most frequently up-regulated miRNAs in human cancer. It is over-expressed in a large fraction of glioblastoma, liver, bladder, and thyroid, pancreatic, gastric, and prostate carcinomas [10]. The miR221-222 cluster is located on the X chromosome. They are involved in the regulation of cell cycle and apoptosis. They are well known for their deregulations in various malignancies and are among the first group of miRNAs shown to be deregulated in thyroid cancer [9]. It has been observed that there is an inverse correlation between the expression of miR-221 and some cell cycle inhibitors, such as CDKN1C/ p57 [CDKI] [11]. The cyclin-dependent kinase inhibitor CDKN1B/p27 is also a direct target of miR-221 [12]. In fact, decreased expression of both $\mathrm{CDKN} 1 \mathrm{C} / \mathrm{p} 57$ and $\mathrm{CDKN} 1 \mathrm{~B} / \mathrm{p} 27$ happens in response to miR221 transfection and a significant over expression of both CDKN1C/ p57 and CDKN1B/p27 happens in response to anti-miR-221 transfection [13]. MiR-221 is up-regulated [5-fold] in PTC, which leads to reduction in the protein level of p27 [Kip1] in PTC tumors [14]. MiR-146b is currently one of the most studied miRNAs in PTC. MiR$146 \mathrm{~b}$ appears to be a prognostic factor for PTC, as it is associated with aggressive clinicopathological features and a poor clinical outcome [15]. In one study, miR-146b was the most consistently overexpressed miRNA in PTC. Two genetic loci, one on chromosome $5 \mathrm{q} 33$ and one on chromosome 10q24, encode miR-146a and miR-146b, respectively. These two loci differ by only two nucleotides. The expression profiles of miR-146a and miR-146b are both upregulated in PTCs. In several PTC samples, miR-146b was more highly expressed than miR-146a, and its increased expression was associated with greater aggressiveness of thyroid tumours [16]. In the present study, we revealed that miR-221 and miR-146b expression were significantly overexpressed in serum

*Corresponding author: Sina Mirzaahmadi, Department of the Genetics, Zanjan branch, Islamic Azad University, Zanjan, Iran, Tel: 44865179-82, 44865154-8; E-mail: sinacanmir@yahoo.com

Received Novembert 07, 2016; Accepted January 22, 2017; Published January 24 2017

Citation: Molaei J, Meidanchi M, Mirzaahmadi S (2017) The Stature of Human Thyroid Cancer Related to Over Expressed mir-221 and mir-146b. J Mol Biomark Diagn S2: 030. doi:10.4172/2155-9929.S2-030

Copyright: ( 2017 Molaei J, et al. This is an open-access article distributed under the terms of the Creative Commons Attribution License, which permits unrestricted use, distribution, and reproduction in any medium, provided the original author and source are credited 
Citation: Molaei J, Meidanchi M, Mirzaahmadi S (2017) The Stature of Human Thyroid Cancer Related to Over Expressed mir-221 and mir-146b. J Mol Biomark Diagn S2: 030. doi:10.4172/2155-9929.S2-030

Page 2 of 8

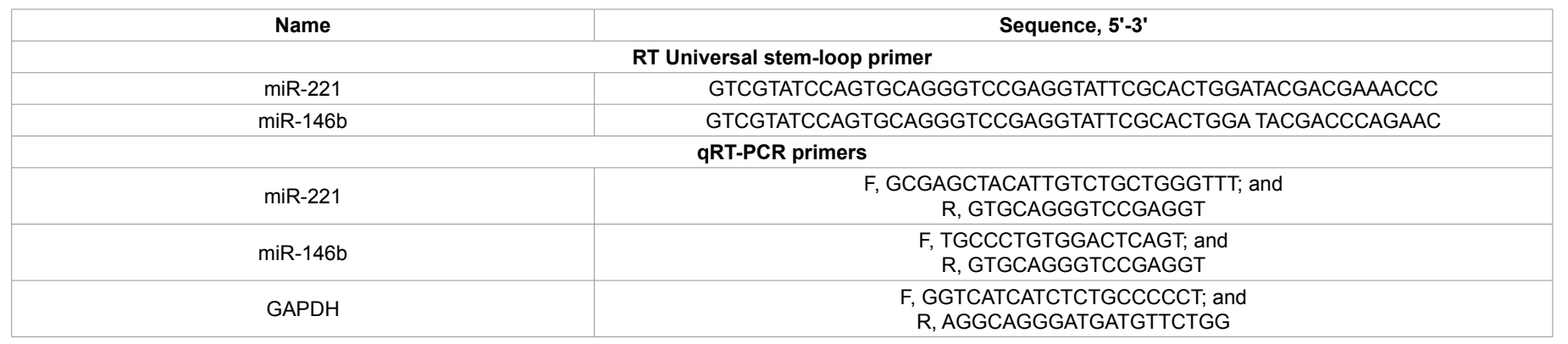

Table 1: Primers for RT or amplification of the mature miR-221, miR-146b and GAPDH mRNA.

samples of PTC in comparison with controls and the benign nodules and thyroidectomy patients, which could be serve as novel biomarkers for early detection of Papillary Thyroid Carcinoma.

\section{Materials and Methods}

\section{Human serum samples}

The Shariaty Hospital collected biological samples and clinical data from patients. All patients gave written consent for sample and ongoing data collection, and practices and procedures were approved by the Shariaty Human Research Ethics Committees [Ref. No. IR.TUMS. EMRI.REC.1394.0037]. The 4 groups were selected for sampling. The sample size was estimated in each group 25 members, based on the following equation.

Equation 1:

$$
\mathrm{n}=\frac{\left(\mathrm{Z}_{1-\frac{\alpha}{2}}+\mathrm{Z}_{1-\beta}\right)^{2}\left[\delta_{1}^{2}+\delta_{2}^{2}\right]}{\left[\mu_{1}-\mu_{2}\right]^{2}}
$$

Which $\alpha=0.05$ and $\beta=0.2$ and $\mu_{1}=1.38$ and $\mu_{2}=0.64, \delta_{1}=0.97$ and $\delta_{2}=0.42$ [17]. Peripheral blood was collected in EDTA anticoagulation tubes from 25 healthy controls, 25 PTC patients the day before thyroidectomy, 25 patients with benign nodules and 25 patients after surgery during the scheduled medical examinations. None of the controls had previously been diagnosed with a thyroid malignancy.

\section{Extraction of total RNA from the serum}

The total RNA including small RNAs were extracted from $100 \mu \mathrm{l}$ of the blood serum according to the manufacturer's instructions by using the miTotalTM RNA Extraction Miniprep System Kit [Cat.NO. VTR1001, Viogene BioTek Corp.]. RNA quality was measured with the Thermo Scientific NanoDrop Lite Spectrophotometer (ND-Lite spectrophotometer; Thermo Fisher Scientific, Inc., Wilmington, DE, USA). The quantity of total RNA isolated was from $50-100 \mathrm{ng} / \mu \mathrm{l}$. The eluted RNA stored at $-70^{\circ} \mathrm{C}$.

\section{Stem-loop qRT-PCR assay design}

In this study, it was used a stem-loop qRT-PCR procedure to quantify the expression of the miR-221 and miR-146b. Glyceraldehyde3 -phosphate dehydrogenase [GAPDH] is one of the most common internal control genes and is mostly used to evaluate gene expression data [18]. Small RNA specific stem-loop was designed based on stemloop quantitative PCR assay design free software (http://genomics. dote.hu:8080/mirnadesigntool/). Mature small RNA sequences used to design the qRT-PCR assays and the designed oligonucleotides used in this study are listed in Table 1 [19].

\section{Reverse transcription with miRNA-specific stem-loop primers}

Almost $0.5 \mu \mathrm{g}$ total RNA was used to perform reverse transcription of RNA with the CinnaGen First Strand cDNA synthesis Kit [Cat. No. RT5209]. First $1 \mu \mathrm{M}$ miRNA-specific stem-loop primer was added to total RNA and incubated at $65^{\circ} \mathrm{C}$ for $5 \mathrm{~min}$ and then snapped on ice for $2 \mathrm{~min}$. So the total RNA got denatured. A mixture of $2 \mathrm{X}$ Buffer M-MuLV, 2U M-MuLV Reverse Transcriptase and $1 \mathrm{mM}$ dNTPs was mixed with the denatured RNA product and volume was brought to $20 \mu \mathrm{l}$ with RNase-Free water. The RT reaction was performed in a total volume of $20 \mu \mathrm{l}$ at $42^{\circ} \mathrm{C}$ for $60 \mathrm{~min}$, then the enzymes were deactivated at $85^{\circ} \mathrm{C}$ for $5 \mathrm{~min}$ and finally the RT product were produced. Meanwhile, the negative controls with no template (NTC) were included in RT reaction, separately.

\section{Quantification of the miR-221, miR-146b and GAPDH expression by $\mathrm{qRT}$-PCR}

Real-time PCR was performed with Roto-Gene 2000 [Corbett Research, Australia] in a total volume of $20 \mu \mathrm{l}$ per reaction in triplicate. We placed $2 \mu \mathrm{l}$ of RT product described previously into an $18 \mu \mathrm{l}$ reaction mixture that contained 1X SYBR Green Master mix [PARSGENOME MiR-Amp kit], $2 \mu \mathrm{M}$ primer mix of the forward primers and the reverse primers, $2 \mu \mathrm{l}$ cDNA product as a $10 \%$ of total volume of PCR reaction brought top up to $20 \mu \mathrm{l}$ with diethyl pyro carbonate [DEPC] $\mathrm{H}_{2} \mathrm{O}$. The cycling protocol consisted of three steps: first, an initial denaturation, $5 \mathrm{~min}$ at $95^{\circ} \mathrm{C}$ to deactivating the RT enzyme; second, 40 cycles of denaturation at $95^{\circ} \mathrm{C}$ for $5 \mathrm{~s}$, annealing $63^{\circ} \mathrm{C}$ for $20 \mathrm{~s}$ and extension at $72^{\circ} \mathrm{C}$ for $30 \mathrm{~s}$, and the third, Plate-reading of fluorescence signals, meltcurve analysis from 70 to $90^{\circ} \mathrm{C}$. Real-time PCR for GAPDH gene was performed in the same manner, by using the corresponding primers.

\section{Statistical Analysis}

In our study, quantization was achieved using the comparative $\mathrm{C}_{\mathrm{T}}$ and Pfaffl method, normalization versus the GAPDH gene as a house keeping gene.

\section{Comparative $\mathrm{C}_{\mathrm{T}}$}

The expression level of miR-221, miR-146b in comparative to the GAPDH were assessed using the $2^{-\Delta \Delta \mathrm{Ct}}$ method. Briefly, the $\mathrm{C}_{\mathrm{T}}$ of fluorescence was determined for each sample [20]. $\Delta \mathrm{C}_{\mathrm{T}}$ indicates the difference in expression levels between miR-221, miR-146b and GAPDH $\left[\Delta \mathrm{C}_{\mathrm{T}}=\mathrm{C}_{\mathrm{T}}\right.$ miR-221 - $\left.\mathrm{C}_{\mathrm{T}} \mathrm{GAPDH}\right],\left[\mathrm{C}_{\mathrm{T}}=\mathrm{C}_{\mathrm{T}}\right.$ miR-146b - $\mathrm{C}_{\mathrm{T}}$ GAPDH] , and $\Delta \Delta \mathrm{C}_{\mathrm{T}}$ indicates the difference in the $\Delta \mathrm{C}_{\mathrm{T}}$ value between the control/normal and for example the PTC $\left[\Delta \Delta \mathrm{C}_{\mathrm{T}}=\Delta \mathrm{C}_{\mathrm{T}}\right.$ control $\Delta \mathrm{C}_{\mathrm{T}} \mathrm{PTC}$. The $2^{-\Delta \Delta \mathrm{Ct}}$ value [fold-value] was calculated.

\section{Pfaffl method}

To identify the most significant differentially expressed miR-221, miR-146b between samples and control, we performed a supervised 
Citation: Molaei J, Meidanchi M, Mirzaahmadi S (2017) The Stature of Human Thyroid Cancer Related to Over Expressed mir-221 and mir-146b. J Mol Biomark Diagn S2: 030. doi:10.4172/2155-9929.S2-030

Page 3 of 8

\begin{tabular}{|c|c|c|c|c|c|}
\hline Sample & GAPDH $C_{T}$ & $\operatorname{miR}-221 C_{T}$ & $\begin{array}{l}\Delta \mathrm{C}_{\mathrm{T}} \text { (Avg. GAPDH - Avg. } \\
\text { miR221) }\end{array}$ & $\begin{array}{l}\Delta \Delta \mathbf{C}_{\mathrm{T}}\left(\text { Avg. } \Delta \mathbf{C}_{\mathrm{T}}-\right. \\
\text { Avg. } \Delta \mathbf{C}_{\mathrm{T}} \text { control) }\end{array}$ & $\begin{array}{l}\text { Normalized miR-221 expression } \\
\text { relative to control } 2^{-\triangle \Delta C T}\end{array}$ \\
\hline Control & 30.83 & 27.70 & 3.12 & - & 1.00 \\
\hline PTC & 31.75 & 17.26 & 14.49 & -11.36 & $2,635.75$ \\
\hline Benign nodule & 30.62 & 26.10 & 4.52 & -1.39 & 2.63 \\
\hline \multirow[t]{2}{*}{ Thyroidectomy } & 30.79 & 28.08 & 2.70 & 0.42 & 0.75 \\
\hline & Sum of Squares & df & Mean Square & $\mathbf{F}$ & Sig. \\
\hline Between Groups & 2330.507 & 3 & 776.836 & 163.242 & 0.000 \\
\hline Within Groups & 456.844 & 96 & 4.759 & & \\
\hline Total & 2787.351 & 99 & & & \\
\hline
\end{tabular}

Table 2: Alteration of miR-221 expression level relative to the GAPDH.

\begin{tabular}{|c|c|c|c|c|c|}
\hline Sample & ${\text { GAPDH } C_{T}}$ & $\operatorname{miR}-146 b C_{T}$ & $\begin{array}{c}C_{\mathrm{T}} \text { (Avg. GAPDH - Avg. miR- } \\
146 \mathrm{~b})\end{array}$ & $\begin{array}{c}\Delta \mathrm{C}_{\mathrm{T}} \text { (Avg. } \Delta \mathrm{C}_{\mathrm{T}}- \\
\text { Avg. } \Delta \mathrm{C}_{\mathrm{T}} \text { control) }\end{array}$ & $\begin{array}{l}\text { Normalized miR-146b } \\
\text { expression } \\
\text { relative to control } 2 \text { - } \triangle \triangle C T\end{array}$ \\
\hline Control & 30.8328 & 28.49 & 2.3416 & - & 1.00 \\
\hline PTC & 31.7544 & 12.65 & 19.0996 & -16.7580 & $110,830.85$ \\
\hline Benign nodule & 30.6216 & 26.31 & 4.3140 & -1.9724 & 3.92 \\
\hline \multirow[t]{2}{*}{ Thyroidectomy } & 30.7944 & 28.53 & 2.2676 & 0.0740 & 0.95 \\
\hline & Sum of Squares & df & Mean Square & $\mathbf{F}$ & Sig. \\
\hline Between Groups & 4942.77 & 3 & 1647.592 & 310.714 & 0.000 \\
\hline Within Groups & 509.05 & 96 & 5.303 & & \\
\hline Total & 5451.827 & 99 & & & \\
\hline
\end{tabular}

Table 3: Alteration of miR-146 expression level relative to the GAPDH.

analysis by Relative expression software tool [REST], proposed by Pfaffl et al. [21], which compares two groups, with up to 16 data points in the sample group versus 16 data points in the control group, and tests the group differences for significance with a newly developed randomization test [22]. The relative expression ratio of a target gene is computed, based on its real-time PCR efficiencies [E] and the crossing point $[\mathrm{CP}]$ difference $[\Delta]$ of an unknown sample versus a control $[\Delta \mathrm{CP}$ control - sample]. In mathematical models the target gene expression is normalized by a non-regulated reference gene expression, e.g. derived from housekeeping genes [GAPDH].

Equation 2:

$$
\text { ratio }=\frac{\left[\mathrm{E}_{\text {miR-221 }}\right]^{\Delta \mathrm{CP}_{\text {mir[Control-Sample }]}}}{\left[\mathrm{E}_{\text {GAPDH }}\right]^{\Delta \mathrm{CP}_{\mathrm{GAPDH}[\text { [control-Sample }]}}}
$$

Equation 2 shows a mathematical model of relative expression ratio in real-time PCR. The ratio of miR-221,146b gene is expressed in a sample versus a control in comparison to GAPDH gene.

\section{Results}

\section{Serum miR-221 in PTC}

Alteration of miR-221 expression level relative to the reference GAPDH in healthy controls, PTC patients, patients with benign nodules and patients after thyroidectomy were assessed (Table 2).

Data were analyzed with SPSS software, version 12.0 (SPSS Inc., Chicago, IL, USA) and Excel software (Microsoft, Redmond, USA). One-way ANOVA and Bonferroni tests were used to investigate the association between controls and other types. $\mathrm{P}<0.001$ was considered to indicate a statistically significant difference.

The mean $( \pm \mathrm{SD}) \Delta \mathrm{C}_{\mathrm{T}}$ value was $14.491 \pm 3.259$ in the 25 samples from patients with PTC and $3.127 \pm 2.220$ in healthy controls and 4.52 \pm 1.52 in benign nodules and $-2.70 \pm 1.081$ in thyroidectomy $(\mathrm{P}<0.001)$.

Serum miR-221 was significantly up regulated in patients with PTC in compared to healthy donors, whereas no significance was observed in thyroidectomy Serum miR-221 expression in compared to healthy controls.

\section{Serum miR-146b in PTC}

Alteration of miR-146b expression level relative to the reference GAPDH in healthy controls, PTC patients, patients with benign nodules and patients after thyroidectomy were assessed (Table 3).

The mean $( \pm \mathrm{SD}) \Delta \mathrm{C}_{\mathrm{T}}$ value was $19.099 \pm 3.498$ in the 25 samples from patients with PTC and $2.341 \pm 1.959$ in healthy controls and $4.314 \pm 1.684$ in benign nodules and $-2.267 \pm 1.514$ in thyroidectomy $(\mathrm{P}<0.001)$.

Serum miR-146b was significantly up regulated in patients with PTC in compared to healthy donors, whereas no significance was observed in thyroidectomy Serum miR-146b expression in compared to healthy controls.

After inserting data to the Rest software, the following results reported:

1. MiR-221 is UP-regulated in papillary group [in comparison to control group] by a mean factor of 4.696 [S.E. range is $2.309-9.460$ ]. MiR-221 papillary group is different to control group. $\mathrm{P}$ [H1] $=0.000$. MiR-146b is UP-regulated in papillary group [in comparison to control group] by a mean factor of 9.853 [S.E. range is 6.217 - 15.227]. MiR$146 \mathrm{~b}$ papillary group is different to control group. $\mathrm{P}$ [H1] $=0.000$ (Figure 1).

2. MiRNA-221 benign group is not different to control group. $\mathrm{P}$ $[\mathrm{H} 1]=0.116$. MiRNA-146b benign group is not different to control group. $\mathrm{P}[\mathrm{H} 1]=0.070$ (Figure 2 ).

3. MiR-221 thyroidectomy group is not different to normal group. $\mathrm{P}[\mathrm{H1}]=0.517$. MiRNA-146b thyroidectomy group is not different to control group. $\mathrm{P}[\mathrm{H1}]=0.889$ (Figure 3 ).

\section{Dual comparison of Serum miR-221 \& miR-146b in PTC}

Box plots of miRNA CT value in sera of patients with PTC ( $\mathrm{n}=$ $25)$ and benign thyroid nodules $(n=25)$ and thyroidectomy $(n=25)$ in comparison with healthy controls $(n=25)$. The levels of serum miR-221 
Citation: Molaei J, Meidanchi M, Mirzaahmadi S (2017) The Stature of Human Thyroid Cancer Related to Over Expressed mir-221 and mir-146b. J Mol Biomark Diagn S2: 030. doi:10.4172/2155-9929.S2-030

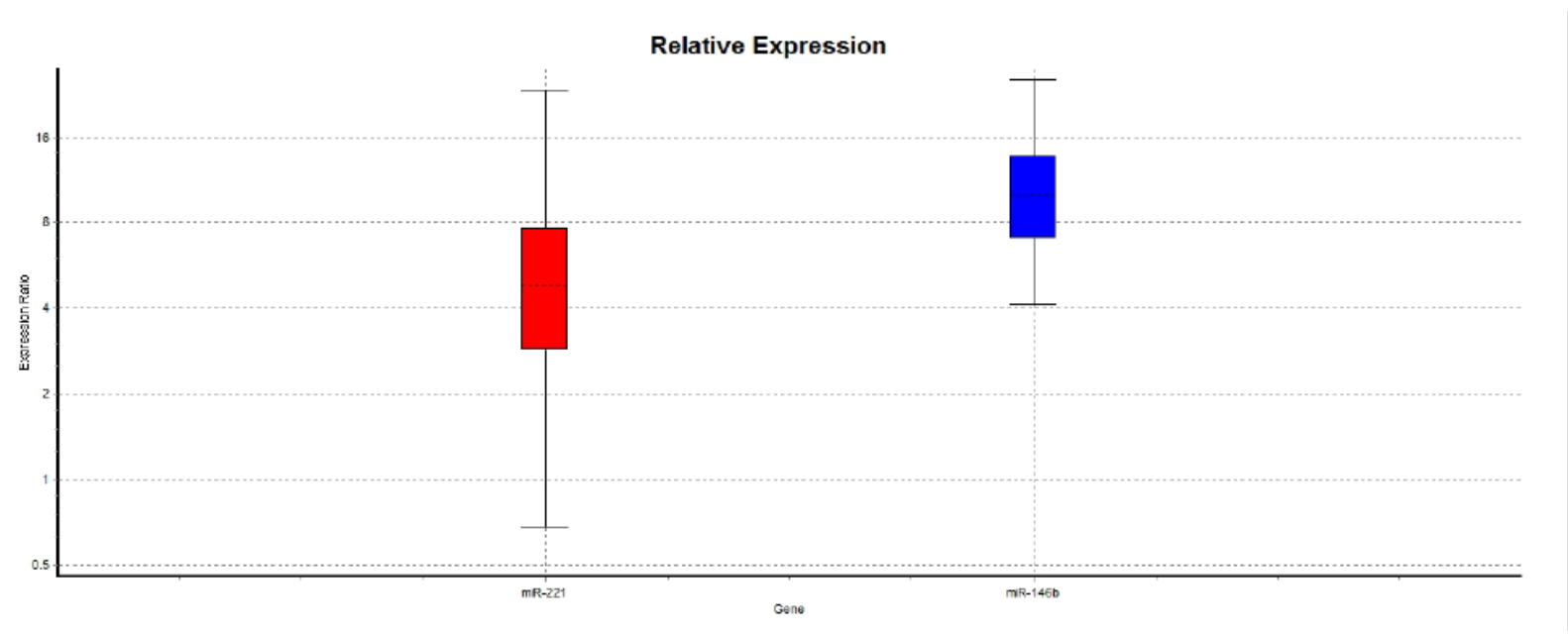

Figure 1: MiR-221 is UP-regulated in papillary group (in comparison to control group) by a mean factor of 4.696 (S.E. range is 2.309 - 9.460 ), MiR-221 papillary group is different to control group, $\mathrm{P}(\mathrm{H} 1)=0.000 \mathrm{MiR}-146 \mathrm{~b}$ is UP-regulated in papillary group (in comparison to control group) by a mean factor of 9.853 (S.E. range is 6.217 15.227), MiR-146b papillary group is different to control group, $\mathrm{P}(\mathrm{H} 1)=0.000$.

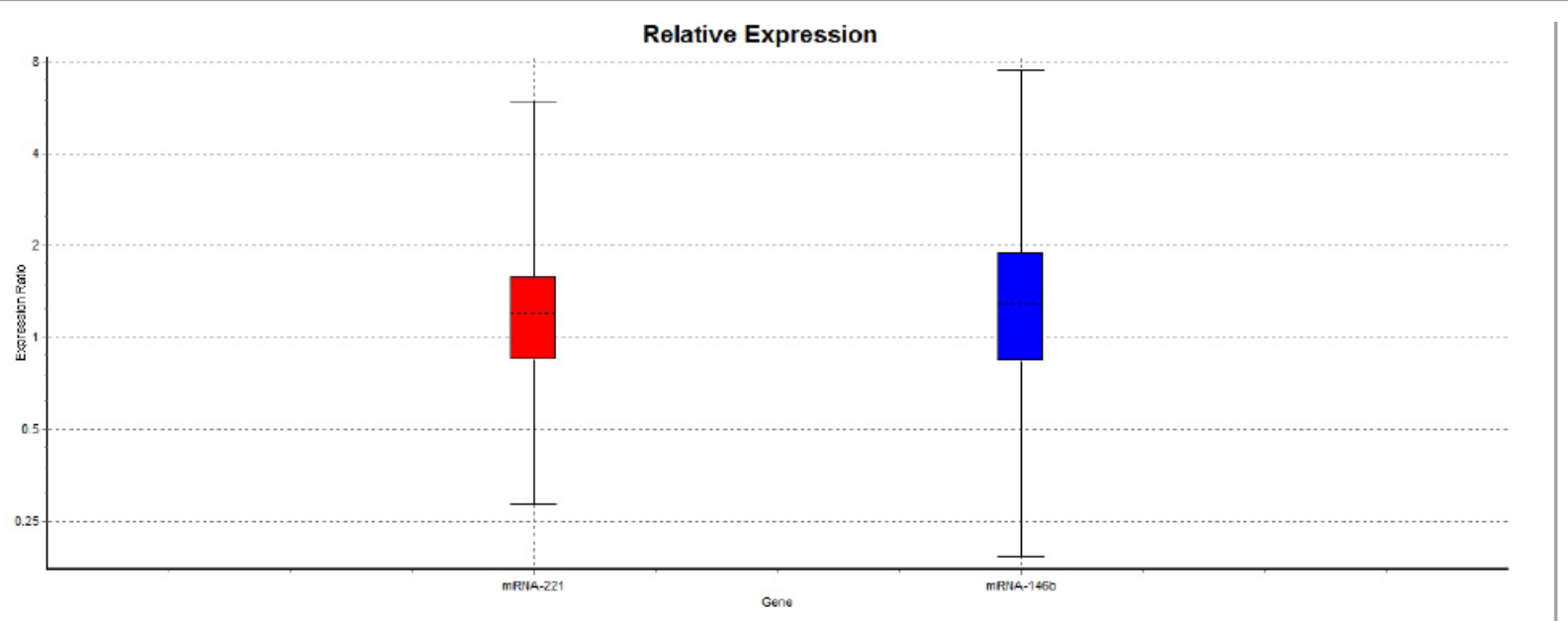

Figure 2: MiRNA-221 benign group is not different to control group, $\mathrm{P}(\mathrm{H} 1)=0.116$, MiRNA-146b benign group is not different to control group, $\mathrm{P}(\mathrm{H} 1)=0.070$.

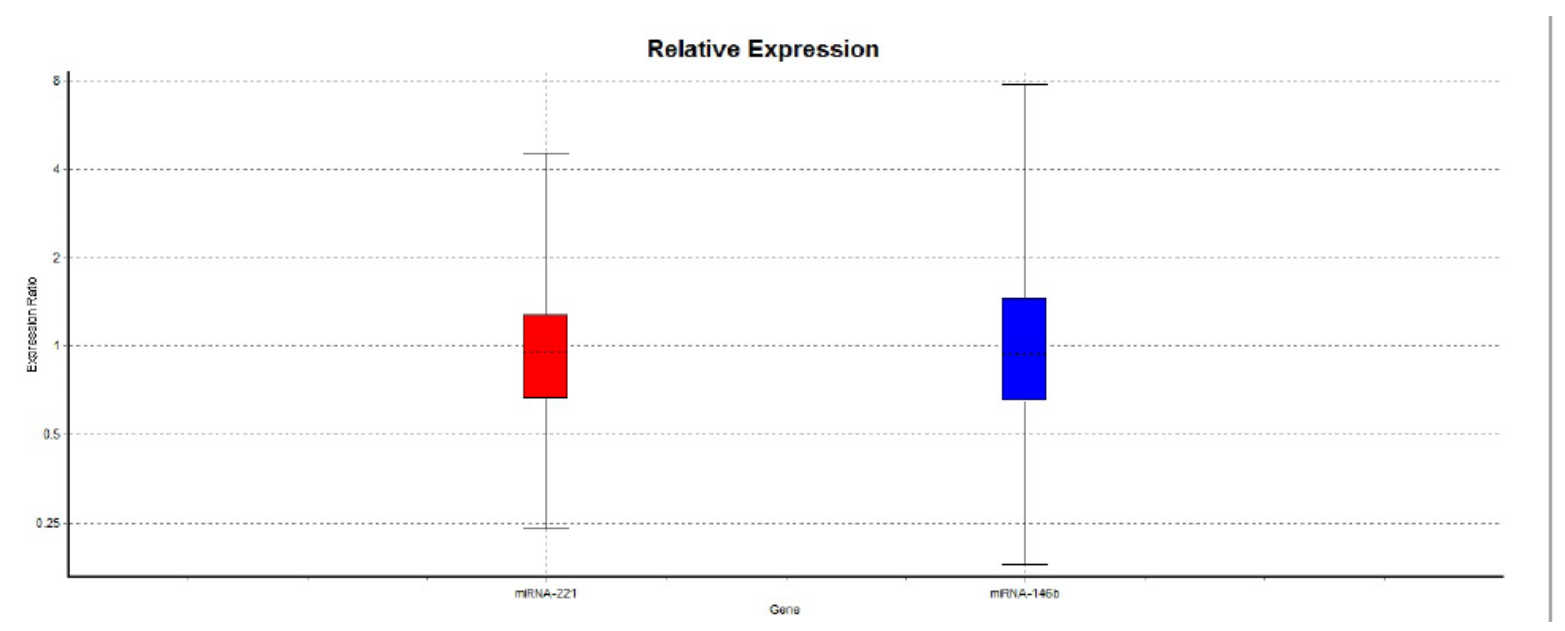

Figure 3: MiR-221 thyroidectomy group is not different to normal group, $\mathrm{P}(\mathrm{H} 1)=0.517$, MiRNA-146b thyroidectomy group is not different to control group, $\mathrm{P}(\mathrm{H} 1)=0.889$. 


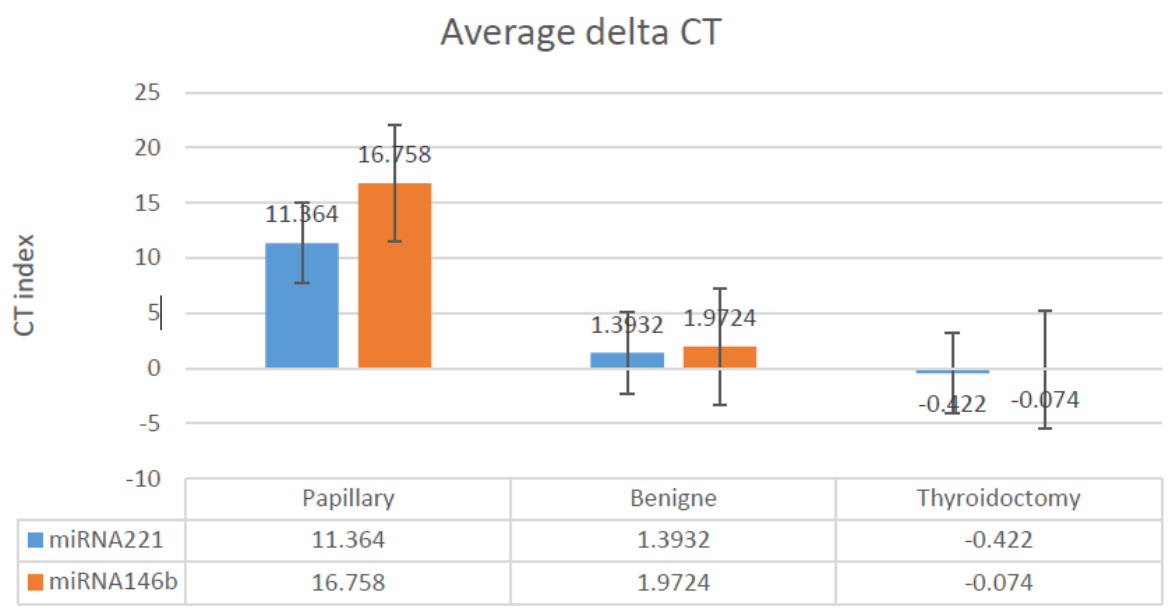

Figure 4: Box plots of miRNA CT value in sera of patients with PTC $(n=25)$ and benign thyroid nodules $(n=25)$ and thyroidectomy $(n=25)$ in comparison with healthy controls $(n=25)$, The levels of serum miR-221 (Blue), miR-146b (Orange) were significantly higher in PTC patients than in patients with benign nodules and thyroidectomy.

(Blue), miR-146b (Orange) were significantly higher in PTC patients than in patients with benign nodules and thyroidectomy (Figure 4).

\section{Discussion}

Several microarray analysis study indicated that 11 miRNAs were deregulated, by at least 2-fold, in PTC compared to benign nodules. Four were down-regulated (miR-122, miR-183, miR-149, and miR514a) and seven were up-regulated (miR-146b, miR-222, miR-221, miR-10b, miR-199a/miR-199b, miR-203 and miR-32) [23,24]. MiR221, miR-222 and miR-146b were also up-regulated in experimental models of thyroid tumorigenesis [16,25]. Increasing evidence shows that cancer-derived exosomes contain miRNAs, which regulate the proliferation of recipient cells. In indolent PTC, PTC-derived exosomes contain miR-146b and miR-222, which alter proliferation of other cells in a complex manner [26]. He et al. identified a miRNA expression signature consisting of 23 miRNAs, of which 17 showed overexpression between 1.5-fold to 19.3-fold, and six showed less than 2 -fold reduction in expression. Five overexpressed miRNAs were sufficient to predict cancer status, and the three most overexpressed miRNAs, miR-146, miR-221, and miR-222, were associated with the down-regulation of KIT gene [27]. The miRNA-chromatin immunoprecipitation microarray assay revealed up-regulation of a set of miRNAs, including miR-221, miR-222, miR-146, miR-21, miR-155, miR-181a, and miR$181 \mathrm{~b}$, in PTCs compared with those in normal thyroid as well as a series of down-regulated miRNAs, such as miR-26a-1,miR-219-5p, and miR-345 [28]. Many publications have reported that PTC samples with different degrees of aggressiveness present different microRNA expression profiles, on the basis of microarrays and qRT-PCR analyses. These studies revealed the common up-regulation of the wellcharacterized miR-146b-5p, miR-221-3p and miR-222-3p in aggressive PTC compared to non-aggressive samples but no commonly down regulated microRNAs [24]. Through to investigations, it was revealed that miRNAs found in the exosomes are associated with a variety of specific diseases such as cancer, for example, research has shown that exosomes in blood circulation are similar to exosomes in the origin of their cancer cells. This suggests that miRNAs in exosomes have the potential to diagnose cancer [29]. In patients with papillary thyroid cancer, over expression of miR-146b in the blood might act as a diagnostic indicator [30]. Several recent studies, including our results, have provided evidence that overexpression of miR-146b plays a critical role in PTC progression and patient prognosis [31]. Furthermore, miRNA signatures have been investigated in thyroid cancer, and researchers have found that miRNA expression profiles were able to differentiate benign from malignant thyroid lesions, suggesting that miRNAs might serve as diagnostic biomarkers for thyroid cancer. However, different accuracies and conflicting results were obtained in different research studies [32-34]. Another study suggested that the results using a panel of 4 miRNAs (miR-328, miR-21, miR-197, and miR-221), which yielded a sensitivity of $86 \%$ and a specificity of $85 \%$ in discriminating malignant from benign nodules, were higher than those obtained from a panel of 2 miRNAs (miR-21 and miR-328), which yielded a sensitivity of $71 \%$ and a specificity of $85 \%$, or than those obtained using the individual miR-21, with a sensitivity of $69 \%$ and a specificity of $86 \%$, indicating that panels consisting of multiple miRNAs possessed higher diagnostic accuracy [35]. In addition, Shen et al. found that the diagnostic utility of miR-221, miR-146b, miR187, and miR-30d in PTC, follicular variant of PTC (FPTC), follicular thyroid cancer (FTC), and anaplastic thyroid carcinoma [ATC] could differentiate malignant from benign lesions with a sensitivity of $93.2 \%$ and a specificity of $93.8 \%$. However, when the 4 miRNAs were used in PTC, FTC and FPTC without ATC, the sensitivity dropped to $88.9 \%$ and the specificity dropped to $78.3 \%$, suggesting that the relative frequencies of FTCs might have an influence on the results of diagnostic value estimation, and also that it may be more difficult to distinguish FTCs from benign lesions [36]. Despite years of attempt to identify tumor marker for human cancers, no tumor marker has generated the excitement that has accompanied the fondness in the potential of miRNAs [37]. In recent decade, many researchers have shown that miRNAs expression is deregulated in many types of human carcinomas, including thyroid. Among the differentially expressed miRs, miR-221, miR-222 and miR-146b were the most highly upregulated. Our study indicates that an upregulation of miR-221 and miR-146b expression in blood samples can differentiate PTC from normal, benign thyroid nodules and thyroidectomy patients. The miR-221 and miR-146b are relatively stable in most body fluids and, making these small RNA molecules ideal biomarkers for differential diagnostic applications.

\section{Conclusion}

This study shows that miR-221 and miR-146b, which are overexpressed in PTC, could play a significant role in a novel 
Citation: Molaei J, Meidanchi M, Mirzaahmadi S (2017) The Stature of Human Thyroid Cancer Related to Over Expressed mir-221 and mir-146b. J Mol Biomark Diagn S2: 030. doi:10.4172/2155-9929.S2-030

Page 6 of 8

diagnostic approach and suggests a critical role of miR-221 and miR146b overexpression in thyroid tumorigenesis.

Collectively, the overexpression of miR-221 and miR-146b could be potentially served as serum indicator biomarkers in the approach for Thyroid Papillary Carcinoma detection from benign nodules.

\section{References}

1. Krátký J, Vítková H, Bartáková J, Telička Z, Antošová M, et al. (2014) Thyroid nodules: Pathophysiological insight on oncogenesis and novel diagnostic techniques. Physiol Res 63: S263-S75.

2. Suresh R, Sethi S, Ali S, Giorgadze T, Sarkar F (2015) Differential expression of microRNAs in papillary thyroid carcinoma and their role in racial disparity. $J$ Cancer Sci Ther 7:145-54.

3. Grogan RH, Mitmaker EJ, Clark OH (2010) The evolution of biomarkers in thyroid cancer-from mass screening to a personalized biosignature. Cancers 2: 885-912.

4. De Guire V, Robitaille R, Tétreault N, Guérin R, Ménard C, et al. (2013) Circulating miRNAs as sensitive and specific biomarkers for the diagnosis and monitoring of human diseases: promises and challenges. Clinical biochemistry 46: 846-60.

5. Hsiao SJ, Nikiforov YE (2014) Molecular approaches to thyroid cancer diagnosis. Endocr Relat Cancer 21: T301-313.

6. Wang C, Lu S, Jiang J, Jia X, Dong X, et al. (2014) Hsa-microRNA-101 suppresses migration and invasion by targeting Rac1 in thyroid cancer cells. Oncology letters 8: 1815-1821.

7. Budhu A, Ji J, Wang XW (2010) The clinical potential of microRNAs. J Hemato Oncol 3: 37.

8. Selth L, Townley S, Bert A, Stricker P, Sutherland P, et al. (2013) Circulating microRNAs predict biochemical recurrence in prostate cancer patients. Bjc 109: $641-50$

9. Zhang R, Hardin H, Chen J, Guo Z, Lloyd RV (2016) Non-coding RNAs in thyroid cancer. Endocrine Pathology 27: 12-20.

10. Lupini L, Bassi C, Ferracin M, Bartonicek N, D'Abundo L, et al. (2013) miR221 affects multiple cancer pathways by modulating the level of hundreds messenger RNAs. Frontiers in genetics.

11. Yang J, Zhang JY, Chen J, Xu Y, Song NH, et al. (2014) Prognostic role of microRNA-221 in various human malignant neoplasms: A meta-analysis of 20 related studies. PloS one 9: e87606.

12. Galardi S, Mercatelli N, Giorda E, Massalini S, Frajese GV, et al. (2007) miR-221 and miR-222 expression affects the proliferation potential of human prostate carcinoma cell lines by targeting p27Kip1. Journal of Biological Chemistry 282 23716-23724

13. Fornari F, Gramantieri L, Ferracin M, Veronese A, Sabbioni S, et al. (2008) MiR-221 controls CDKN1C/p57 and CDKN1B/p27 expression in human hepatocellular carcinoma. Oncogene 27: 5651-5661.

14. De La Chapelle A, Jazdzewski K (2011) MicroRNAs in thyroid cancer. The J Clin Endocrinol Metab 96: 3326-3336.

15. Santisteban $P$ (2016) Advances in molecular pathogenesis of thyroid cancer. Endocrine Abstracts.

16. Pallante P, Battista S, Pierantoni GM, Fusco A (2014) Deregulation of microRNA expression in thyroid neoplasias. Nature Reviews Endocrinology 10: 88-101.

17. Yu S, Liu Y, Wang J, Guo Z, Zhang Q, Yu F, et al. (2012) Circulating microRNA profiles as potential biomarkers for diagnosis of papillary thyroid carcinoma. The J Clin Endocrinol Metab 97: 2084-2092.

18. Barber RD, Harmer DW, Coleman RA, Clark BJ (2005) GAPDH as a housekeeping gene: analysis of GAPDH mRNA expression in a panel of 72 human tissues. Am Physiological Soc 21: 389-395.

19. Czimmerer Z, Hulvely J, Simandi Z, Varallyay E, Havelda Z, et al. (2013) A versatile method to design stem-loop primer-based quantitative PCR assays for detecting small regulatory RNA molecules. PloS one 8: e55168.

20. Esen H, Erdi F, Kaya B, Feyzioglu B, Keskin F, et al. (2015) Tissue thioredoxin reductase-1 expression in astrocytomas of different grades. Journal of neurooncology 121: 451-458.

21. Pfaffl MW, Horgan GW, Dempfle L (2002) Relative expression software tool [REST@] for group-wise comparison and statistical analysis of relative expression results in real-time PCR. Nucleic acids research 30: e36.

22. Pfaffl MW (2001) A new mathematical model for relative quantification in realtime RT-PCR. Nucleic acids research 9: e45.

23. Andrade L, Melo P, Neto W, Andrade C, Margotto M, et al. (2013) Marcadores moleculares en el cáncer de tiroides. Revista argentina de endocrinología y metabolism 50: 84-98.

24. Saiselet M, Gacquer D, Spinette A, Craciun L, Decaussin-Petrucci M, et al. (2015) New global analysis of the microRNA transcriptome of primary tumors and lymph node metastases of papillary thyroid cancer. BMC genomics 16: 828

25. Yuan ZM, Yang ZL, Zheng Q (2014) Deregulation of microRNA expression in thyroid tumors. Journal of Zhejiang University Science B 15: 212-224.

26. Yang Q, Diamond MP, Al-Hendy A (2016) The emerging role of extracellular vesicle-derived miRNAs: implication in cancer progression and stem cell related diseases. J Clin Epigenet 2: 13.

27. Zhang W, Dahlberg JE, Tam W (2007) MicroRNAs in tumorigenesis: a primer Am j pathol 171: 728-738.

28. Huang C, Cai Z, Huang M, Mao C, Zhang Q, et al. (2014) miR-219-5p modulates cell growth of papillary thyroid carcinoma by targeting estrogen receptor a. J Clin Endocrinol Metab 100: E204-E13.

29. Reid G, Kirschner MB, Van Zandwijk N (2010) Circulating microRNAs: Association with disease and potential use as biomarkers. Critical reviews in oncology/hematology 80: 193-208.

30. He H, Jazdzewski K, Li W, Liyanarachchi S, Nagy R, et al. (2005) The role of microRNA genes in papillary thyroid carcinoma. Proc Natl Acad Sci USA 102 19075-19080.

31. Chou CK, Chi SY, Huang CH, Chou FF, Huang CC, et al. (2016) IRAK1, a Target of miR-146b, Reduces Cell Aggressiveness of Human Papillary Thyroid Carcinoma. J Clin Endocrinol Metab 101: 4357-4366.

32. Keutgen XM, Filicori F, Crowley MJ, Wang Y, Scognamiglio T, et al. (2012) A panel of four miRNAs accurately differentiates malignant from benign indeterminate thyroid lesions on fine needle aspiration. Clin Cancer Res 18 2032-2038.

33. Lee YS, Lim YS, Lee JC, Wang SG, Park HY et al (2015) Differentia expression levels of plasma-derived miR-146b and miR-155 in papillary thyroid cancer. Oral oncol 51: 77-83.

34. Mazeh $\mathrm{H}$ (2012) MicroRNA as a diagnostic tool in fine-needle aspiration biopsy of thyroid nodules. Oncologist 17: 1032-1038.

35. Keutgen XM, Filicori F, Fahey III TJ (2013) Molecular diagnosis for indeterminate thyroid nodules on fine needle aspiration: advances and limitations. Expert Rev Mol Diagn 13: 613-623.

36. Shen R, Liyanarachchi S, Li W, Wakely Jr PE, Saji M, et al. (2012) MicroRNA signature in thyroid fine needle aspiration cytology applied to "atypia of undetermined significance" cases. Thyroid 22: 9-16.

37. Bartels CL, Tsongalis GJ (2009) MicroRNAs: Novel biomarkers for human cancer. Clin chem 55: 623-631.

This article was originally published in a special issue, Cancer Biomarker handled by Editor(s). Dr. Sudhir Srivastava, Cancer Biomarkers Research Group, National Institute of Health, USA; Dr. Shou-Jiang Gao, The University of Texas Health Science Centre at San Antonio, USA; Dr. Kenneth Maiese, University of Medicine \& Dentistry of New Jersey, New Jersey Medical School, USA 